Wouters, H., Dijk, L. van, Geffen, E.C.G. van, Gardarsdottir, H., Stiggelbout, A.M., Bouvy, M.L. Primary-care patients' trade-off preferences with regard to antidepressants. Psychological Medicine: 2014, 44(11), 2301-2308

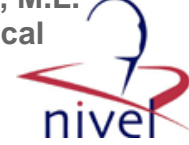

\begin{tabular}{|l|l|}
\hline $\begin{array}{l}\text { Postprint } \\
\text { Version }\end{array}$ & 1.0 \\
\hline Journal website & $\underline{\text { http://journals.cambridge.org/action/displayAbstract?fromPage=online\&aid=9145 }}$ \\
\hline Pubmed link & $\underline{\underline{\text { http://www.ncbi.nlm.nih.gov/pubmed/?term=24398071 }}}$ \\
\hline DOI & $10.1017 /$ S0033291713003103 \\
\hline
\end{tabular}

This is a NIVEL certified Post Print, more info at http://www.nivel.eu

\title{
Primary-care patients' trade-off preferences with regard to antidepressants
}

\author{
H. WOUTERS ${ }^{A 1}$ c1, L. VAN DiJK ${ }^{\text {A2 }}$, E. C. G. VAN GEFFEN ${ }^{A 1}$, H. GARDARSDOTTIR ${ }^{A 1 A 3}$, A. M. \\ STIGGELBOUT $^{\mathrm{A4}}$ AND M. L. BOUVY ${ }^{\mathrm{A} 1}$ \\ ${ }^{a 1}$ Division of Pharmaco-epidemiology and Clinical Pharmacology, Faculty of Science, \\ Utrecht Institute for Pharmaceutical Sciences (UIPS), Utrecht University, Utrecht, The \\ Netherlands \\ ${ }^{a 2}$ NIVEL, Netherlands Institute for Health Services Research, Utrecht, The Netherlands \\ ${ }^{\text {a3 }}$ Department of Clinical Pharmacy, Laboratory and Pharmacy Division, University Medical \\ Centre Utrecht, The Netherlands \\ ${ }^{\mathrm{a} 4}$ Department of Medical Decision Making, Leiden University Medical Centre, Leiden, The \\ Netherlands
}

\begin{abstract}
Background Antidepressants are frequently prescribed but results regarding their efficacy have been equivocal for different spectra of the severity continuum and their side-effects are often burdensome. Non-adherence is a likely consequence. The objective was therefore to examine patients' trade-offs between the efficacy, side-effects and other drawbacks of antidepressants and whether these trade-offs predicted non-adherence.

Method Trade-offs from 225 antidepressant users, recruited through community pharmacies, were assessed with an Adaptive Conjoint Analysis (ACA) choice task that was customized to each individual patient. From the estimated utilities, relative importance scores of treatment properties were calculated. Nonadherence was measured through self-report and pharmacy refill data.

Results Relapse prevention and symptom relief were on average equally important. Side-effects were as important and the side-effect stomach and intestine complaints was on average even slightly more important than relapse prevention and symptom relief. Additional treatment with psychotherapy was preferred by $61 \%$ of the patients. A benefit/drawback ratio revealed that $18 \%$ of the patients did not consider the efficacy to outweigh the drawbacks. A higher benefit/drawback ratio was associated with a decreased odds of intentional nonadherence [odds ratio (OR) 0.2, 95\% confidence interval (CI) 0.07-0.7, Wald = 6.7, $p=0.01$ ).

Conclusions For nearly one in five patients, the efficacy of antidepressants does not outweigh their drawbacks. Knowing patients' trade-offs is likely to aid both
\end{abstract}


Wouters, H., Dijk, L. van, Geffen, E.C.G. van, Gardarsdottir, H., Stiggelbout, A.M., Bouvy, M.L. Primary-care patients' trade-off preferences with regard to antidepressants. Psychological Medicine: 2014, 44(11), 2301-2308

physicians and patients to identify important treatment preferences, to improve adherence and to make more deliberate decisions on whether or not to continue treatment.

\section{Correspondence}

${ }^{\mathrm{c} 1}$ Address for correspondence: H. Wouters, Ph.D., Division of Pharmacoepidemiology and Clinical Pharmacology, Faculty of Science, Utrecht Institute for Pharmaceutical Sciences (UIPS), Utrecht University, PO Box 80082, 3508 TB, Utrecht, The Netherlands. (Email: j.wouters@uu.nl)

\section{INTRODUCTION}

The number of people in the industrialized world who are treated with antidepressants is remarkably high. In 2005-2008, approximately 10\% of citizens in the USA (Pratt et al.2011) were treated with antidepressants. In The Netherlands, almost 6\% of citizens were treated with antidepressants in the years 2008-2012 (Gipdatabank, 2012). Nevertheless, contradictory findings about the efficacy of antidepressants have been obtained for different spectra of the severity continuum. Two meta-analyses found antidepressants to effectively reduce symptoms (Gibbons et al.2012) and to prevent relapse (Geddes et al.2003), whereas a third refuted the efficacy of antidepressants for mild to moderate depression (Kirsch et al.2008). At the same time, antidepressants often cause side-effects (Masand, 2003) that may impose a burden on patients. Together, these findings may explain the high rates of non-adherence, which have been found to range from 13\% up to 70\% (Pampallona et al.2002; ten Doesschate, 2009).

There is evidence that patients' decisions to continue treatment, antidepressants in this case, are likely to be governed by trade-offs between the benefits and drawbacks of the drugs. Aikens et al. (2005), for instance, showed that adherence was highest when patients' perceived necessity exceeded their perceived concerns and lowest when their perceived concerns exceeded their perceived necessity of antidepressants. Trade-offs are particularly likely when the benefits and drawbacks are competing, for instance when the efficacy is equivocal or when high efficacy is accompanied by the burden of side-effects. As mentioned, both instances seem to apply to patients who are treated with antidepressants.

In this study we examined how patients weigh the benefits or efficacy of antidepressants versus their drawbacks such as common side-effects and other treatment aspects. Specifically, we examined whether patients for whom the benefits of antidepressants did not outweigh the drawbacks were at risk for non-adherence. In addition, we studied the following treatment aspects. First, with regard to the benefits of antidepressants, we studied the value that patients assign to the efficacy in terms of symptom relief versus the efficacy in terms of relapse prevention. Patients who assign more value to symptom relief might need careful adherence monitoring during the maintenance phase when symptoms have mainly disappeared but the aim is to prevent relapse of depression or anxiety. Second, we examined to what extent patients value psychotherapy in addition to treatment with antidepressants. As patients often prefer psychotherapy to antidepressants (van Schaik et al.2004), the option of psychotherapy in addition to treatment with antidepressants might also 
Wouters, H., Dijk, L. van, Geffen, E.C.G. van, Gardarsdottir, H., Stiggelbout, A.M., Bouvy, M.L. Primary-care patients' trade-off preferences with regard to antidepressants. Psychological Medicine: 2014, 44(11), 2301-2308

represent an important treatment aspect. Incorporating patients' preferences in such a way into the decision process may improve its informed and patient-physician shared character (Michie et al.2002; Pieterse et al.2010). Third, we examined whether trade-offs differ as a function of patients' demographic and clinical characteristics because non-adherence has been reported to be associated with educational level (Brook et al.2006), marital status (Masand, 2003), depression severity (Sirey et al.2001; Brown et al.2005) and age (Sirey et al.2001; Yen et al.2009).

Conjoint analysis choice tasks provide a superior assessment of patients' preferences compared to conventional preference questionnaires. These tasks have previously been used to assess patients' trade-offs with regard to various treatments (Fraenkel et al.2004; Beusterien et al.2007; Ahmed et al.2008; Pieterse et al.2010). Instead of calculating a balance score in which the perceived drawbacks are subtracted from the perceived benefits of treatment, conjoint analysis choice tasks ask patients to make choices between hypothetical treatment options of which one is more attractive in one respect but less attractive in another respect than the other and vice versa (see Method). In this way, patients have to make trade-off choices that reflect their weighting of the benefits and drawbacks of treatment. Because, in reality, no such thing as the perfect treatment exists, such trade-off choosing is likely to mimic actual choices that patients make in the real world. Thus, conjoint analysis choice tasks assess patient trade-offs in a more direct manner than conventional preference questionnaires that assess benefits and drawbacks with independent items.

Accordingly, using conjoint analysis, the objectives were to examine patients' tradeoffs between the benefits and drawbacks of antidepressants and their preferences with regard to relevant treatment aspects. Furthermore, we examined associations between patients' trade-offs and demographic and clinical characteristics in addition to non-adherence.

\section{METHOD}

\section{Participants}

Between January and August 2012, primary-care patients were recruited randomly from community pharmacies by H.W. and an intern. Patients were invited to participate if they had been treated in the past year with tricyclic antidepressants (TCAs), selective serotonin reuptake inhibitors (SSRIs) or other antidepressants including serotonin-norepinephrine reuptake inhibitors and tetracyclic antidepressants. For ethical reasons, we excluded all patients who were likely to suffer from severe or terminal illness, psychotic disorders or dementia as inferred from their medicine prescriptions. Patients were also excluded in cases of psychosocial and socio-economic problems on the discretion of the pharmacist. Patients participated by filling out an online questionnaire. Interviews were conducted in the pharmacy with older and non-adherent patients to reduce selection bias of participation by only patients with access to the internet. For all participants, refill data were extracted from the automated dispensing records of the pharmacy. The medical ethical committee of Leiden University Medical Centre approved the study. After a complete description of the study, informed consent was obtained from all participants. 
Wouters, H., Dijk, L. van, Geffen, E.C.G. van, Gardarsdottir, H., Stiggelbout, A.M., Bouvy, M.L. Primary-care patients' trade-off preferences with regard to antidepressants. Psychological Medicine: 2014, 44(11), 2301-2308

\section{Preferences for different antidepressant characteristics}

Patients' preferences were elicited by an Adaptive Conjoint Analysis (ACA) task (www.sawtooth.com), showing patients 15 pairs of hypothetical treatment options, with one option presented on the right and the other on the left. Each option consisted of two treatment characteristics, so-called attributes, that reflected the benefits and drawbacks of antidepressants and that were described on favourable and less favourable levels. Each presented pair of treatment options required a patient to make a trade-off choice as the left treatment option had a more attractive level of one of the attributes (e.g. efficacy) but a less attractive level of the other attribute (e.g. weight gain as a side-effect) compared to the right treatment option. Fig. 1 shows an example of one of the presented pairs. Patients had to rate their preference on a ninepoint scale (from 1 = strong preference for the left treatment option to $9=$ strong preference for the right treatment option). ACA is adaptive because it customizes the hypothetical treatment options to an individual's previous choices. Thus, ACA presents trade-offs that are increasingly relevant to patients (Sawtooth, 2007).

\section{[FIGURE 1]}

Selection of treatment attributes and their levels was based on literature with regard to antidepressants and focus groups conducted with primary-care patients who were being treated with antidepressants. As benefits, 'prevention of relapse of depression or anxiety' (ten Doesschate et al.2009) and 'symptom relief' (Masand, 2003) were selected. As side-effects, 'decreased libido’ (Brill, 2004; van Geffen et al.2007; Uher et al.2009), 'sweating' (van Geffen et al.2007; Uher et al.2009), 'weight gain' (Masand, 2003; van Geffen et al.2007) and 'stomach and intestine complaints' (Masand, 2003; Uher et al.2009) were selected. 'Regimen duration' (van Geffen et al.2007, 2009), 'limitations in alcohol use' (Kalichman et al.2005) and 'additional treatment with psychotherapy’ (van Schaik et al.2004) were selected as other treatment aspects. To facilitate understanding of the attributes, side-effects were described in layman's language and numerical attributes were described in words, for example $20 \%$ as ' 2 out of 10 '.

Subsequently, the ACA program (Sawtooth, 2007) estimated, for each patient, a utility for each level of every treatment attribute. Utilities were estimated on a scale ranging from approximately -4 to +4 . The higher the utility of an attribute level, the higher the attractiveness of that attribute level for a patient. Based on the utility estimates, a relative importance percentage for each treatment characteristic or attribute was calculated (see online Appendix A). This relative importance percentage reflected patients' trade-off preferences with regard to the benefits and drawbacks of antidepressants in terms of the above attributes. Appendix A provides further explanation and an examination of the validity of the estimated utilities.

\section{Therapy non-adherence}

Non-adherence was assessed by self-report and calculated from pharmacy refill data. The items from the new eight-item Morisky Medication Adherence Scale (MMAS-8; Morisky et al.2008), the five-item Medication Adherence Rating Scale (MARS-5; Horne \& Weinman, 1999) and additional questions about forgetting to take antidepressants and persistence were used as self-reported measures of non- 
Wouters, H., Dijk, L. van, Geffen, E.C.G. van, Gardarsdottir, H., Stiggelbout, A.M., Bouvy, M.L. Primary-care patients' trade-off preferences with regard to antidepressants. Psychological Medicine: 2014, 44(11), 2301-2308

adherence. Factor analysis (varimax rotation) and Cronbach's $\alpha$ revealed two scales with good internal consistency: 'unintentional non-adherence' due to forgetfulness and 'intentional non-adherence' of a more conscious nature (see online Appendix B). A Medication Possession Ratio (MPR) was calculated using information on antidepressant dispensing prior to patients' recruitment date. Treatment episodes were constructed that allowed for a 90-day gap between the theoretical end date of an antidepressant prescription and a subsequent antidepressant prescription. In case a dispensing date preceded the theoretical end date of the prior prescription, this overlap was accounted for. For each patient, the MPR was calculated for the last treatment episode prior to recruitment.

\section{Statistical analysis}

Means and standard deviations were calculated for the relative importance score of each attribute. We calculated for how many patients symptom relief was more important than relapse prevention. Furthermore, we calculated a benefit/drawback ratio by dividing the relative importance scores of efficacy (relapse prevention and symptom relief) by the relative importance scores of the other attributes, except for 'additional treatment with psychotherapy'. Associations between this benefit/drawback ratio and patients' demographic and clinical characteristics were examined with linear regression analysis. Associations between the benefit/drawback ratio and non-adherence were examined in three logistic regression models. For that purpose, the total scores of self-reported non-adherence were dichotomized at $<80 \%$ versus $\geq 80 \%$ of the score distribution: unintentional non-adherence (adherent: score of $\leq 2$ versus non-adherent: score $\geq 3$ ) and intentional non-adherence (adherent: score of $\leq 3$ versus non-adherent: score $\geq 4$ ). The MPR was dichotomized at the $80 \%$ cut-off (adherent $\geq 80 \%$ versus non-adherent $<80 \%$ ). Demographic and clinical characteristics were entered as covariates in the regression models when they had univariate associations with non-adherence at a $p$ value $\leq 10 \%$. In the final models, $p$ values $\leq 5 \%$ were considered statistically significant.

\section{RESULTS}

A total of 225 patients participated in this study, with 208 filling out an online questionnaire and 17 taking part in a face-to-face interview. Table 1 presents the demographic and clinical characteristics of the participants.

\section{[TABLE 1]}

\section{Preferences for different antidepressants attributes}

Seven participants did not complete the ACA task and were excluded from further analysis. The average and spread of utilities of the attribute levels and relative importance scores of the attributes are shown in Table 2. Symptom relief was on average of high importance and was considered the most important attribute by $13 \%$ $(n=29)$ of the patients. Although the efficacy of antidepressants with regard to relapse prevention was on average almost as important as the efficacy in terms of symptom relief, more people $(19 \%, n=41)$ considered it the most important attribute. Furthermore, when comparing the attributes symptom relief and relapse 
Wouters, H., Dijk, L. van, Geffen, E.C.G. van, Gardarsdottir, H., Stiggelbout, A.M., Bouvy, M.L. Primary-care patients' trade-off preferences with regard to antidepressants. Psychological Medicine: 2014, 44(11), 2301-2308

prevention, 122 patients (54\%) considered symptom relief as important as, or more important than, relapse prevention.

\section{[TABLE 2]}

The side-effect with the highest average importance was that of stomach and intestine complaints. It was even slightly more important than the efficacy attributes and $27 \%(n=59)$ of the patients considered it most important. Weight gain and decreased libido were also important, with $23 \%(n=51)$ and $7 \%(n=16)$ respectively of the patients considering these attributes most important. Sweating as a side-effect was on average of lower importance and only one patient considered it most important.

Additional psychotherapy was shown to be of intermediate importance, with $10 \%$ (n $=21$ ) of the patients considering it most important. Yet it had large individual variation. A total of 137 patients (61\%) preferred additional psychotherapy to no additional psychotherapy. The additional treatment aspects of restrictions in alcohol consumption and regimen duration were on average the least important of all attributes and none of the patients considered these most important.

\section{Benefit/drawback ratio score and different demographic and clinical characteristics}

The benefit/drawback ratio showed that 39 patients (18\%) considered the efficacy to be less than or equally important compared with the other attributes (ratio of $\leq 1$ ). A higher benefit/drawback ratio was associated with being treated with psychotherapy $(\beta=0.14, \mathrm{t}=2.03, \mathrm{p}=0.04)$ and treatment with an SSRI $(\beta=0.27, \mathrm{t}=3.07, \mathrm{p}<$ $0.01)$, whereas a lower benefit/drawback ratio was observed with increasing age $(\beta=$ $-0.17, \mathrm{t}=-2.58, \mathrm{p}=0.01)$.

\section{Benefit/drawback ratio score and non-adherence}

Moderate agreement was observed between the MPR and self-reported unintentional non-adherence (77\%) and intentional non-adherence (76\%). Age, marital status and receiving psychotherapy were associated with unintentional non-adherence at the univariate level $(\mathrm{p}<0.10)$. No significant association was observed between the benefit/drawback ratio and unintentional non-adherence either before [odds ratio (OR) 1.8, 95\% confidence interval (CI) 0.6-5.6, Wald $=1.0, \mathrm{p}=0.31$ ] or after adjustment for the above-mentioned factors (OR 1.2, 95\% CI 0.3-4.3, Wald $=0.08$, p $=0.77)$. None of the demographic and clinical characteristics were associated with intentional non-adherence at the univariate level $(\mathrm{p}<0.10)$. A higher benefit/drawback ratio was significantly associated with decreased odds of intentional non-adherence (OR 0.2, 95\% CI 0.07-0.7, Wald $=6.7, \mathrm{p}=0.01$ ). Treatment duration had an association with the MPR at the univariate level ( $\mathrm{p}<$ $0.10)$. No significant association was observed between the benefit/drawback ratio and the MPR, either before (OR 1.4, 95\% CI 0.5-4.1, Wald $=0.31, \mathrm{p}=0.58$ ) or after adjusting for treatment duration (OR 1.2, 95\% CI 0.4-3.8, Wald $=0.15, \mathrm{p}=0.70$ ). 
Wouters, H., Dijk, L. van, Geffen, E.C.G. van, Gardarsdottir, H., Stiggelbout, A.M., Bouvy, M.L. Primary-care patients' trade-off preferences with regard to antidepressants. Psychological Medicine: 2014, 44(11), 2301-2308

\section{DISCUSSION}

The three main findings of this study are that patients considered side-effects on average as important as the efficacy of antidepressants, that almost one in five patients had a benefit/drawback ratio indicating that they considered side-effects and other drawbacks of antidepressants equally or more important than the efficacy of antidepressants, and that a higher benefit/drawback ratio was associated with a decreased odds of intentional non-adherence. Together, these findings from the perspective of patients concord with the equivocal findings from three meta-analyses regarding the efficacy of antidepressants (Geddes et al.2003; Kirsch et al.2008; Gibbons et al.2012), the knowledge that antidepressants frequently cause various side-effects (Masand, 2003), and the high rates of non-adherence that have been reported (Pampallona et al.2002; ten Doesschate et al.2009). The rate of one in five patients who considered the side-effects and other drawbacks of antidepressants equally or more important than the efficacy of antidepressants was lower than the rate of about one in four patients found by Aikens et al. (2005) who adopted the Beliefs about Medicines Questionnaire (BMQ) necessity-concerns differential (Horne \& Weinman, 1999) to estimate for how many patients the perceived concerns exceeded the perceived need.

At the same time, it makes sense that the benefit/drawback ratio was not predictive of unintentional non-adherence as this kind of non-adherence often reflects mere forgetting to take tablets. That the benefit/drawback ratio was not predictive of adherence as assessed with the MPR calculated from the pharmacy refill data was an unexpected finding. A possible explanation for this finding could be that the MPR measure reflects both unintentional and intentional non-adherence whereas the benefit/drawback ratio was found to be associated with only intentional nonadherence. Another important finding of this study is that, with regard to the benefit of antidepressants, more than half of the patients considered symptom relief as important as or more important than relapse prevention. Furthermore, the majority of patients preferred additional psychotherapy to no additional psychotherapy. This latter finding is consistent with other studies that suggest that, although prescription of antidepressants fits better into physicians' treatment routines, most patients in fact prefer psychotherapy (van Schaik et al.2004). Finally, a higher benefit/drawback ratio was found for patients being treated with additional psychotherapy whereas a lower benefit/drawback ratio was associated with increasing age. The latter result is consistent with a previous finding showing age to be positively associated with nonadherence (Yen et al.2009) but inconsistent with another finding showing the opposite (Sirey et al.2001).

Knowledge of patients' trade-off preferences has several implications for clinicians. First, it is likely to enhance the shared (Pieterse et al.2010) and informed (Michie et al.2002) character of decision making about treatment. Prescribing antidepressants to a patient who does not consider the benefits of antidepressants to outweigh the drawbacks might reflect inappropriate prescribing from a patient's perspective. Perhaps, for such a patient, treatment with antidepressants is not or no longer needed. Alternatively, psychotherapy instead of, or in addition to, antidepressants could be considered for these patients, particularly for those who favoured additional psychotherapy over no additional psychotherapy. A caveat here that should of course be verified by the physician is that, when a patient does not consider the benefits of 
Wouters, H., Dijk, L. van, Geffen, E.C.G. van, Gardarsdottir, H., Stiggelbout, A.M., Bouvy, M.L. Primary-care patients' trade-off preferences with regard to antidepressants. Psychological Medicine: 2014, 44(11), 2301-2308

antidepressants to outweigh the drawbacks, this could also indicate that a patient has incorrect information or false beliefs about the drawbacks of antidepressants (van Schaik et al.2004). In fact, a formal examination of the presence of false beliefs about antidepressants would require inclusion of such false beliefs as antidepressant treatment attributes in the ACA choice task. Devising such an ACA choice task with some of the treatment attributes reflecting false beliefs about antidepressants would be a valuable avenue for future research.

Instead of deciding that antidepressants are inappropriately prescribed from a patient's perspective, trade-off preferences could also be used for guiding choices or switches between different antidepressants in conjunction with knowledge of the treatment indication and the severity of complaints. Particularly so, when a physician considers a patient's relative importance assigned to individual side-effects because different antidepressants are likely to have different side-effect profiles. However, this too warrants follow-up studies.

Second, knowledge of patients trade-offs might also contribute to a better understanding of non-adherence as a higher benefit/drawback ratio was found to be associated with decreased intentional non-adherence. Furthermore, the half of the patients who assigned equal or more value to efficacy in terms of symptom relief than in terms of relapse prevention might need careful adherence monitoring during the maintenance phase when most symptoms have resolved but the aim is to prevent relapse.

Third, the associations found between the benefit/drawback ratio and treatment with additional psychotherapy and age might also be clinically relevant. The higher benefit/drawback ratio found in this study among patients who were being treated with additional psychotherapy could imply that these patients suffered from more severe complaints. For patients with more severe complaints, the trade-offs would obviously be in favour of the efficacy. Alternatively, this finding might reflect a positive influence of psychotherapy on perceptions of antidepressants. The lower benefit/drawback ratio found among older patients could suggest that the drawbacks of antidepressants have more repercussions for older patients than for younger patients. Alternatively, older patients might appraise symptoms of depression as less dysfunctional and more as part of normal life.

This study has several strengths. A particular strength is the use of ACA. Currently, an often-used approach for assessing trade-offs is a decisional balance score or a subtraction of independently rated drawbacks from benefits (Aikens et al.2005). The ACA choice task, instead, requires immediate trade-off comparisons between alternative treatment options described at more and less favourable attributes. Thereby, ACA choice tasks better reflect the trade-offs that patients make in the real world between the benefits and drawbacks of treatment. Various other researchers have used ACA choice tasks to study, for instance, juvenile patients' trade-off preferences regarding growth hormone injection devices (Ahmed et al.2008), HIV patients' preferences with regard to different antiretroviral therapy options (Beusterien et al.2007), patients' valuing of different types of disease-modifying anti-rheumatic drugs (DMARDs) for treatment of rheumatoid arthritis (Fraenkel et al.2004) and rectal cancer treatment outcomes (Pieterse et al.2010). A strength with regard to the assessment of adherence is that it was assessed through both self-report and pharmacy refill data. 
Wouters, H., Dijk, L. van, Geffen, E.C.G. van, Gardarsdottir, H., Stiggelbout, A.M., Bouvy, M.L. Primary-care patients' trade-off preferences with regard to antidepressants. Psychological Medicine: 2014, 44(11), 2301-2308

There are also limitations to consider. Clinical characteristics were assessed by selfreport and some important clinical characteristics could not be assessed, such as somatic co-morbidity, DSM-IV-TR Axis II disorders and detailed information about treatment history with regard to specific types of antidepressants and different forms of psychotherapy. Furthermore, depression severity was only measured indirectly through the clinical characteristics 'duration of antidepressant treatment', 'admission to a psychiatric ward' and 'treatment with psychotherapy' rather than through a validated depression severity scale. Thus, replication of our study, correlating benefit/drawback ratios with validated depression severity scores, is important. In addition, our examination of patients' preferences was restricted in three aspects. First, as drawbacks, only common side-effects and two other barriers were examined. Hence, other side-effects and practical problems deserve to be included in trade-off choice tasks of future studies. Second, because our study was cross-sectional, it is possible that our findings admix patient's antecedent beliefs and experiences with their current experiences and current levels of depression. For the same reason, we could not study whether preferences changed over time and whether these changes were associated with incident non-adherence. Longitudinal studies in which patients are enrolled at the start of the regimen are therefore recommended. Third, a caveat that should be kept in mind with regard to interpreting the relative importance scores of the treatment attributes is that importance scores depend on the range of the levels of the attributes. It may well be that, although patients may consider the efficacy of antidepressants as extremely important, if the levels of this attribute are not that different and the levels of another attribute in fact are, they may well assign a higher importance to the latter attribute. For that reason we specified the attribute levels as much as possible according to evidence from the literature.

Overall, we conclude that, for approximately one in five patients, the benefits of antidepressants do not outweigh their drawbacks. By knowing patients' trade-offs, shared and informed decision making is likely to be enhanced. This in turn is likely to increase appropriate prescribing of antidepressants and to reduce non-adherence.

\section{Acknowledgements}

We thank all study participants and the community pharmacists and pharmacy interns for their assistance. This study was supported financially by a grant from the Netherlands Organization for Health Research and Development (ZonMw) (grant no. 152002028).

\section{REFERENCES}

Ahmed, SF, Smith, WA, Blamires, C (2008). Facilitating and understanding the family's choice of injection device for growth hormone therapy by using conjoint analysis. Archives of Disease in Childhood93, 110-114.

Aikens, JE, Nease, DE Jr., Nau, DP, Klinkman, MS, Schwenk, TL (2005). Adherence to maintenance-phase antidepressant medication as a function of patient beliefs about medication. Annals of Family Medicine3, 23-30.

Beusterien, KM, Dziekan, K, Schrader, S, Flood, E, Flood, R, Shearer, A, Davis, EA (2007). Patient preferences among third agent HIV medications: a US and German perspective. AIDS Care19, 982-988

Brill, M (2004). Antidepressants and sexual dysfunction. Fertility and Sterility81 (Suppl. 2), 35-40. 
Wouters, H., Dijk, L. van, Geffen, E.C.G. van, Gardarsdottir, H., Stiggelbout, A.M., Bouvy, M.L. Primary-care patients' trade-off preferences with regard to antidepressants. Psychological Medicine: 2014, 44(11), 2301-2308

Brook, OH, van Hout, HP, Stalman, WA, de Haan, M (2006). Nontricyclic antidepressants: predictors of nonadherence. Journal of Clinical Psychopharmacology26, 643-647.

Brown, C, Battista, DR, Bruehlman, R, Sereika, SS, Thase, ME, Dunbar-Jacob, J (2005). Beliefs about antidepressant medications in primary care patients: relationship to selfreported adherence. Medical Care43, 1203-1207.

Fraenkel, L, Bogardus, ST, Concato, J, Felson, DT, Wittink, DR (2004). Patient preferences for treatment of rheumatoid arthritis. Annals of Rheumatic Diseases63, 1372-1378.

Geddes, JR, Carney, SM, Davies, C, Furukawa, TA, Kupfer, DJ, Frank, E, Goodwin, GM (2003). Relapse prevention with antidepressant drug treatment in depressive disorders: a systematic review. Lancet361, 653-661.

Gibbons, RD, Hur, K, Brown, CH, Davis, JM, Mann, JJ (2012). Benefits from antidepressants: synthesis of 6-week patient-level outcomes from double-blind placebocontrolled randomized trials of fluoxetine and venlafaxine. Archives of General Psychiatry69, 572-579.

Gipdatabank (2012). Dutch College of Health Insurance [College voor Zorgverzekeringen]. Horne, R, Weinman, J (1999). Patients' beliefs about prescribed medicines and their role in adherence to treatment in chronic physical illness. Journal of Psychosomatic Research47, 555-567.

Kalichman, SC, Cain, D, Fuhrel, A, Eaton, L, Di Fonzo, K, Ertl, T (2005). Assessing medication adherence self-efficacy among low-literacy patients: development of a pictographic visual analogue scale. Health Education Research20, 24-35.

Kirsch, I, Deacon, BJ, Huedo-Medina, TB, Scoboria, A, Moore, TJ, Johnson, BT (2008). Initial severity and antidepressant benefits: a meta-analysis of data submitted to the Food and Drug Administration. PLoS Medicine5, e45.

Masand, PS (2003). Tolerability and adherence issues in antidepressant therapy. Clinical Therapeutics25, 2289-2304.

Michie, S, Dormandy, E, Marteau, TM (2002). The multi-dimensional measure of informed choice: a validation study. Patient Education and Counseling48, 87-91.

Morisky, DE, Ang, A, Krousel-Wood, M, Ward, HJ (2008). Predictive validity of a medication adherence measure in an outpatient setting. Journal of Clinical Hypertension (Greenwich)10, 348-354.

Pampallona, S, Bollini, P, Tibaldi, G, Kupelnick, B, Munizza, C (2002). Patient adherence in the treatment of depression. British Journal of Psychiatry180, 104-109.

Pieterse, AH, Berkers, F, Baas-Thijssen, MC, Marijnen, CA, Stiggelbout, AM (2010). Adaptive Conjoint Analysis as individual preference assessment tool: feasibility through the internet and reliability of preferences. Patient Education and Counseling78, 224-233.

Pratt, LA, Brody, DJ, Quiping, G (2011). Antidepressant Use in Persons Aged 12 and Over: United States, 2005-2008. Centers for Disease Control and Prevention, NCHS Data Brief, no. 76.

Sawtooth (2007). The ACA/Web v6.0 Technical Paper. Sawtooth Software: Sequim, WA, USA.

Sirey, JA, Bruce, ML, Alexopoulos, GS, Perlick, DA, Friedman, SJ, Meyers, BS (2001). Stigma as a barrier to recovery: perceived stigma and patient-rated severity of illness as predictors of antidepressant drug adherence. Psychiatric Services52, 1615-1620.

ten Doesschate, MC, Bockting, CL, Schene, AH (2009). Adherence to continuation and maintenance antidepressant use in recurrent depression. Journal of Affective Disorders115, 167-170.

Uher, R, Farmer, A, Henigsberg, N, Rietschel, M, Mors, O, Maier, W, Kozel, D, Hauser, J, Souery, D, Placentino, A, Strohmaier, J, Perroud, N, Zobel, A, Rajewska-Rager, A, Dernovsek, MZ, Larsen, ER, Kalember, P, Giovannini, C, Barreto, M, McGuffin, P, Aitchison, KJ (2009). Adverse reactions to antidepressants. British Journal of Psychiatry195, 202-210.

van Geffen, EC, Kruijtbosch, M, Egberts, AC, Heerdink, ER, van Hulten, R (2009). Patients' perceptions of information received at the start of selective serotonin-reuptake inhibitor treatment: implications for community pharmacy. Annals of Pharmacotherapy43, 642-649. van Geffen, EC, van der Wal, SW, van Hulten, R, de Groot, MC, Egberts, AC, Heerdink, ER (2007). Evaluation of patients' experiences with antidepressants reported by means of a medicine reporting system. European Journal of Clinical Pharmacology63, 1193-1199. 
Wouters, H., Dijk, L. van, Geffen, E.C.G. van, Gardarsdottir, H., Stiggelbout, A.M., Bouvy, M.L. Primary-care patients' trade-off preferences with regard to antidepressants. Psychological Medicine: 2014, 44(11), 2301-2308

van Schaik, DJ, Klijn, AF, van Hout, HP, van Marwijk, HW, Beekman, AT, de Haan, M, van Dijck, R (2004). Patients' preferences in the treatment of depressive disorder in primary care. General Hospital Psychiatry26, 184-189.

Yen, CF, Lee, Y, Tang, TC, Yen, JY, Ko, CH, Chen, CC (2009). Predictive value of selfstigma, insight, and perceived adverse effects of medication for the clinical outcomes in patients with depressive disorders. Journal of Nervous and Mental Disease197, 172-177.

\section{TABLES AND FIGURES}

Fig. 1. Example of an Adaptive Conjoint Analysis (ACA) item.

\section{Which option do you prefer?}

Antidepressant A:

\section{relapse of depression or anxiety}

in 5 out of 10 people

a bit weight gain

\section{Antidepressant B:}

relapse of depression or anxiety in 2 out of 10 people

or

moderate to severe weight gain

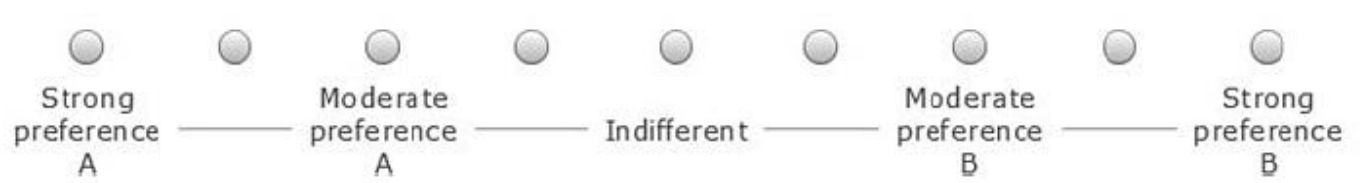


Wouters, H., Dijk, L. van, Geffen, E.C.G. van, Gardarsdottir, H., Stiggelbout, A.M., Bouvy, M.L. Primary-care patients' trade-off preferences with regard to antidepressants. Psychological Medicine: 2014, 44(11), 2301-2308

Table 1. Demographic and clinical characteristics of the participants $(n=225)^{\mathrm{a}}$

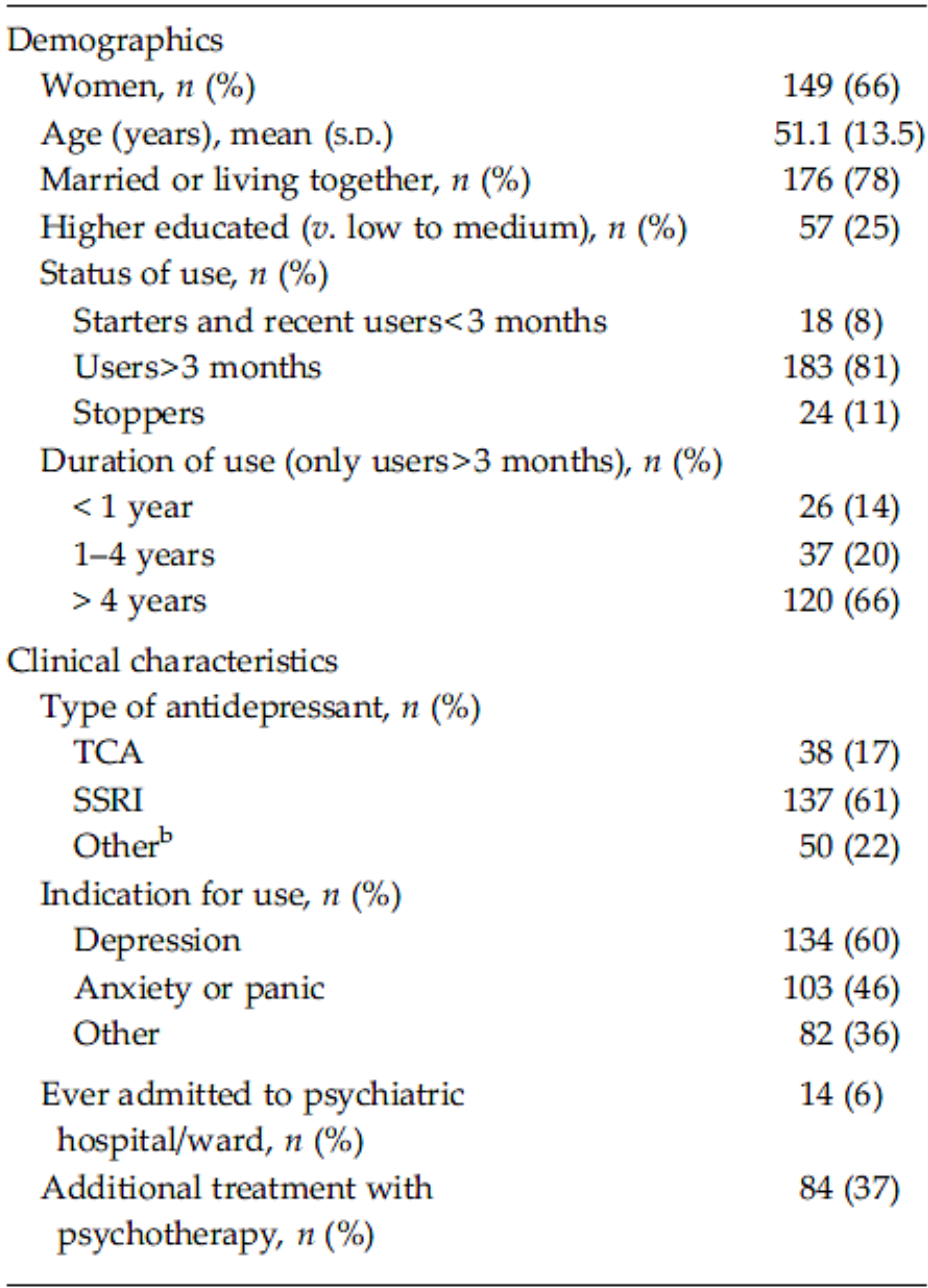

TCA, Tricyclic antidepressant; SSRI, selective serotonin reuptake inhibitor; S.D., standard deviation.

${ }^{a}$ All demographic and clinical characteristics were assessed by self-report except for type of antidepressant.

${ }^{\mathrm{b}}$ Includes serotonin-norepinephrine reuptake inhibitors and tetracyclic antidepressants. 
Wouters, H., Dijk, L. van, Geffen, E.C.G. van, Gardarsdottir, H., Stiggelbout, A.M., Bouvy, M.L. Primary-care patients' trade-off preferences with regard to antidepressants. Psychological Medicine: 2014, 44(11), 2301-2308

Table 2. Utilities and relative importance of treatment attributes

\begin{tabular}{|c|c|c|c|c|}
\hline \multirow{2}{*}{$\begin{array}{l}\text { Treatment attributes } \\
\text { and their levels }\end{array}$} & \multicolumn{2}{|c|}{ Utilities $^{2}$} & \multicolumn{2}{|c|}{$\begin{array}{l}\text { Average } \\
\text { importance }(\%)^{\mathrm{b}}\end{array}$} \\
\hline & Mean & S.D. & Mean & S.D. \\
\hline \multicolumn{5}{|l|}{ Efficacy } \\
\hline Relapse of depression or anxiety & & & 13.8 & 3.3 \\
\hline In five out of 10 people & -0.69 & 0.52 & & \\
\hline In two out of 10 people & 0.71 & 0.47 & & \\
\hline Symptom relief & & & 14.3 & 2.5 \\
\hline To a moderate extent & -0.72 & 0.53 & & \\
\hline To a great extent & 0.74 & 0.49 & & \\
\hline Additional psychotherapy & & & 8.2 & 5.4 \\
\hline No & -0.20 & 0.56 & & \\
\hline Yes & 0.23 & 0.56 & & \\
\hline \multicolumn{5}{|l|}{ Side-effects } \\
\hline Decreased libido & & & 12.4 & 2.6 \\
\hline A bit & 0.63 & 0.40 & & \\
\hline Moderate to severe & -0.60 & 0.44 & & \\
\hline Sweating & & & 11.1 & 2.4 \\
\hline A bit & 0.55 & 0.34 & & \\
\hline Moderate to severe & -0.53 & 0.38 & & \\
\hline Weight gain & & & 14.5 & 2.4 \\
\hline A bit & 0.73 & 0.45 & & \\
\hline Moderate to severe & -0.71 & 0.50 & & \\
\hline Stomach and intestine complaints & & & 15.1 & 1.9 \\
\hline A bit & 0.76 & 0.47 & & \\
\hline Moderate to severe & -0.74 & 0.52 & & \\
\hline \multicolumn{5}{|l|}{ Other treatment aspects } \\
\hline Alcohol use & & & 5.5 & 1.5 \\
\hline Preferably not & -0.26 & 0.24 & & \\
\hline 2-3 glasses a day & 0.28 & 0.19 & & \\
\hline Regimen duration & & & 5.1 & 1.2 \\
\hline 6 months & 0.26 & 0.16 & & \\
\hline 1 year & -0.24 & 0.22 & & \\
\hline
\end{tabular}

S.D., Standard deviation.

a Utilities estimated on a scale ranging from -4 to +4 , the higher the estimated utility value of an attribute level, the more that attribute level is preferred; for example a 1-year regimen duration is less preferred than a 6-month regimen duration.

${ }^{\mathrm{b}}$ The relative importance of each attribute is calculated as follows: for each attribute the difference between the utilities of its levels is divided by the sum of the differences between the utilities for all of the attributes and multiplied by 100 . 